\title{
Instrumental Methods for Differentiation of Frozen-thawed from Fresh Broiler Breast Fillets
}

\author{
Samooel Jung, Jae Cheong Lee ${ }^{1}$, Yeonkuk Jung, Min Kyu Kim, Hwa-Young Son², and Cheorun Jo* \\ Department of Animal Science and Biotechnology, Chungnam National University, Daejeon 305-764, Korea \\ ${ }^{1}$ Animal Products Grading Service, Gunpo 435-010, Korea \\ ${ }^{2}$ College of Veterinary Medicine \& Graduate School of New Drug Discovery and Development, \\ Chungnam National University, Daejeon 305-764, Korea
}

\begin{abstract}
To differentiate between frozen-thawed and fresh broiler breast fillets, different methods such as optical microscopy and measurement of drip loss, $\mathrm{pH}$, torrymeter and $K$-value were performed. A total of 10 samples of fresh and frozen-thawed breast fillets were stored in a refrigerator $\left(4^{\circ} \mathrm{C}\right)$ for $5 \mathrm{~d}$. Optical microscopy of the frozen-thawed breast fillets found structural changes caused by ice crystals, which may have significantly increased drip loss compared to fresh breast fillet. The $\mathrm{pH}$ and $K$-value could not be distinguished between the two breast fillets during storage. However, the torrymeter values of the fresh and frozen-thawed breast fillets were significantly different $(p<0.05)$. The results indicate that both optical microscopy and torrymeter measurement can be effective methods for differentiating between fresh and frozen-thawed breast fillets. However, optical microscopy may be difficult to implement in the marketplace since it requires much time and effort. Thus, the determination of the torrymeter value is the easiest and most rapid instrumental method among those tested for the differentiation of frozen-thawed chicken breast fillet from fresh one.
\end{abstract}

Key words: breast fillet, fresh, frozen-thawed, differentiation, instrument

\section{Introduction}

Chicken meat occupies a large part of protein consumption in Korea. The per capita consumption of chicken meat was $12.7 \mathrm{~kg}$ in 2009 (Korea Chicken Council, 2009), and this rate is higher than those of pork and beef (Choe et al., 2009). Chicken meat is distributed in the marketplace in both fresh and frozen form, although almost all imported chicken meats are frozen. Freezing of meat has adverse effects on meat quality, specifically textural and nutritional deterioration (Addis, 1986), although it is an efficient way of increasing shelf-life. As such, fresh chicken meat is preferred by consumers and sold at a higher price than frozen meat. For this reason, frozen-thawed chicken meats sometimes illegally mixed with fresh ones and sold as fresh chicken meat. This fact may cause distrust in consumers and eventually affect domestic industry, which is already encountering obstacles due to the impending

\footnotetext{
*Corresponding author: Cheorun Jo, Department of Animal Science and Biotechnology, Chungnam National University, Daejeon 305-764, Korea. Tel: 82-42-821-5774, Fax: 82-42825-9754, E-mail: cheorun@cnu.ac.kr
}

Free Trade Agreement and other external environmental changes.

To prevent illegal sales and to protect consumers, a proper method for the differentiation between fresh and frozenthawed chicken meat is necessary. An enzymatic method using 3-hydroxyacyl-CoA-dehydrogenase released by the disruption of mitochondria was reported to distinguish between fresh and frozen-thawed meat (Gottesmann and Hamm, 1983). In addition, several methods, including DNA-based techniques, spectroscopy and microscopy (Al Jowder et al., 1997; Carroll et al., 1981; Grayling et al., 1996) have been developed for this purpose. However, these methods are not entirely applicable to a real market setting due to their long operation time, high cost and need for trained personnel. Therefore, the development and evaluation of an easy, rapid and reliable differentiation method between fresh and frozen-thawed chicken meat is urgently needed.

Therefore, the objective of this study was to identify an easy, rapid and reliable instrumental method for the differentiation between fresh and frozen-thawed chicken breast fillets among current techniques. 


\section{Materials and Methods}

\section{Sample preparation}

Fresh and frozen-thawed broiler breast fillets (10 pairs per each treatment) were obtained from Cherrybro Co., Ltd. (Jincheon, Korea). For the frozen-thawed sample, the chicken breasts were frozen for $24 \mathrm{~h}$ in a $-40^{\circ} \mathrm{C}$ deep freezer $30 \mathrm{~min}$ after slaughter and then thawed in a $4^{\circ} \mathrm{C}$ refrigerator for $48 \mathrm{~h}$. For the fresh sample, the chicken breasts were stored in a refrigerator $30 \mathrm{~min}$ after slaughter. Different instrumental measurements were performed during storage for $5 \mathrm{~d}$ at $4^{\circ} \mathrm{C}$ refrigerator.

\section{Optical microscopy}

To measure the histological changes of chicken breast by freezing, the microscopic analysis was performed at storage day of 1,2 , and 3 . At each day, samples were cut $(0.5 \times 0.5 \times 0.5 \mathrm{~cm})$ and fixed with $10 \%$ formalin for $24 \mathrm{~h}$ in isopentane chilled with liquid nitrogen $\left(-160^{\circ} \mathrm{C}\right)$. Thin transverse serial sections (5 $\mu \mathrm{m}$ thickness) were sliced using a cryostat, mounted on slides and then air-dried $\left(40^{\circ} \mathrm{C}\right)$. Sections were stained using Hematoxylin Eosin Safran coloration to visualize overall muscle structure. Observation was performed at 200-1,000 $\times$ magnification using an optical microscope (BX51, Olympus Co., Japan).

\section{Drip loss}

The whole breast fillets (right-side) were left for $24 \mathrm{~h}$ at $4^{\circ} \mathrm{C}$, after which the drip loss was measured by weighing the samples and comparing with the initial sample weight. Drip loss was calculated by the following equation.

\section{Drip loss (\%)} $=\frac{\text { Initial weight of sample }- \text { Final weight of sample }}{\text { Initial weight of sample }} \times 100$

\section{pH}

The $\mathrm{pH}$ of the sample was measured for $5 \mathrm{~d}$ at $24 \mathrm{~h}$ intervals. Breast meat $(1 \mathrm{~g})$ was then homogenized (T25b, Ika Works (Asia), Malaysia) in $9 \mathrm{~mL}$ of distilled water at $1,130 \mathrm{~g}$ for $1 \mathrm{~min}$. Then, the homogenate was centrifuged at $2.090 \mathrm{~g}$, after which the resulting supernatant was used to measure $\mathrm{pH}$ using a pH meter (750P, Istec Co., Korea).

\section{Torrymeter measurement}

A torrymeter (GR Torry Fish Freshness Meter, Distell Industries Ltd., UK) was used to directly measure the electrical properties of the breast fillets stored at $4^{\circ} \mathrm{C}$. Two sensors of the torrymeter were placed firmly against the outside skin of each the left breast fillet in order to eliminate air pockets between the sensors. The torrymeter gives a response ranging from 0 (advanced decomposition) to 16 (very fresh).

\section{$K$-value}

The breast fillets $(1 \mathrm{~g})$ were homogenized (T25b, Ika Works (Asia), Malaysia) in $5 \mathrm{~mL} 0.7 \mathrm{M}$ perchloric acid at $1,130 \mathrm{~g}$ for $1 \mathrm{~min}$. The homogenate was centrifuged again at $2.090 \mathrm{~g}$, after which the supernatant was filtered using filter paper (No. 4, Whatman Ltd. Kent, UK). The filtrate was placed in a test tube $(50 \mathrm{~mL})$ and adjusted to a pH of 6.5 with $7 \mathrm{~N} \mathrm{KOH}$. This solution was used for measurement of the $K$-value using a freshness checker system (HF-1000, Hutech Co., Ltd, Korea). The manufacturer's instructions for obtaining the $K$-value are as follows:

$$
K \text {-value }(\%)=\frac{\mathrm{HxR}+\mathrm{Hx}}{\mathrm{ATP}+\mathrm{ADP}+\mathrm{AMP}+\mathrm{IMP}+\mathrm{HxR}+\mathrm{Hx}} \times 100
$$

Abbreviations: ATP: Adenosine-5'-triphosphate, ADP: Adenosine-5'-diphosphate, AMP: Adenosine-5'-monophosphate, IMP: Inosine-5'-monophosphate, HxR: Inosine, Hx: Hypoxanthine

\section{Statistical analysis}

Analysis of variance was performed using raw data, and the mean values and standard deviations were calculated using Statistical Analysis System (SAS, 2002). Differences among the means were determined by Duncan's multiple range test with significance defined at $p \leq 0.05$.

\section{Results and Discussion}

\section{Optical microscopy}

Freezing is generally known as an effective method for increasing the shelf-life of meat with relatively small deteriorations in quality. However, freezing is still accompanied by certain morphological changes (Do et al., 2004). Frozen-thawed breast fillets underwent extension of the spaces between its muscle fibers compared to fresh breast fillets (Fig. 1). During the freezing process, the space between the muscle fibers became larger and the myofibrils collapsed. These changes are in good agreement with previous reports (Do et al., 2004; Ngapo et al., 1999; Zhu et al., 2004). These reports indicated that the histological changes in muscle structure caused by freezing are due to ice crystals that are created during the freezing process, which then induce deterioration of tex- 

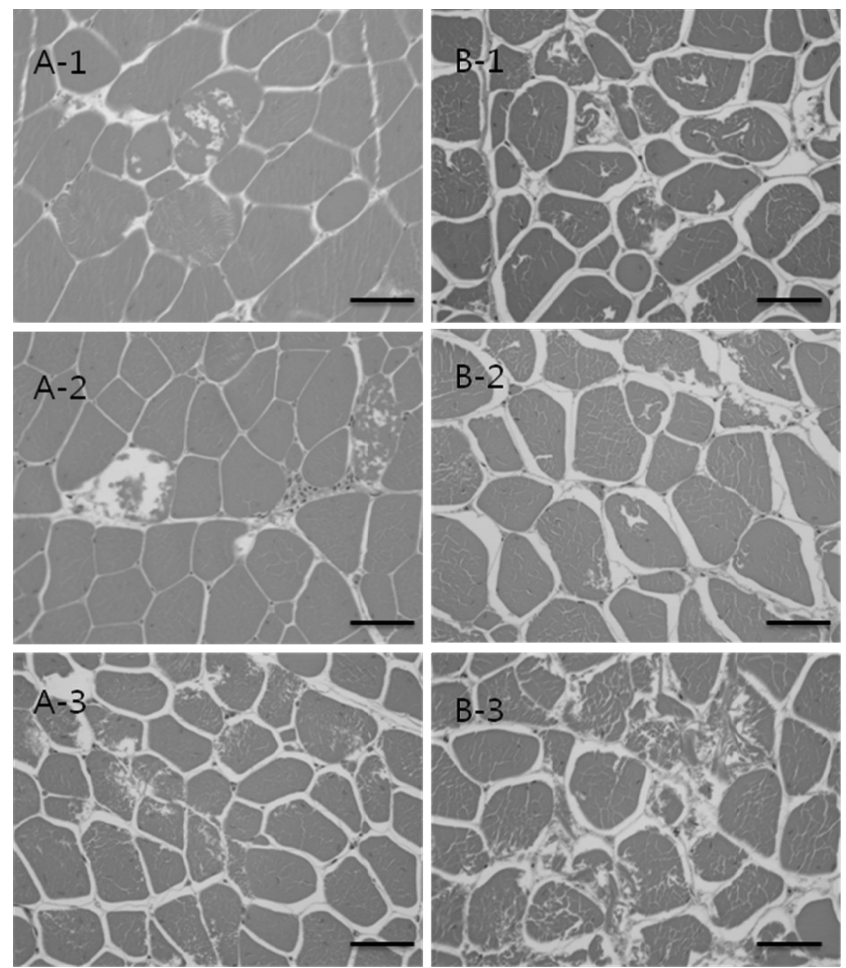

Fig. 1. Optical microscopy of fresh (A) and frozen-thawed breast fillets (B). A-1, Storage for $24 \mathrm{~h}$ at $4^{\circ} \mathrm{C}$ after postmortem; A-2, Storage for $48 \mathrm{~h}$ at $4^{\circ} \mathrm{C}$ after postmortem; A-3, Storage for $72 \mathrm{~h}$ at $4^{\circ} \mathrm{C}$ after postmortem; B-1, Storage for $24 \mathrm{~h}$ at $4^{\circ} \mathrm{C}$ after freezing for $24 \mathrm{~h}$ and thawing; B2, Storage for $24 \mathrm{~h}$ at $4^{\circ} \mathrm{C}$ after freezing for $48 \mathrm{~h}$ and thawing; B-3, Storage for $24 \mathrm{~h}$ at $4^{\circ} \mathrm{C}$ after freezing for 72 $\mathrm{h}$ and thawing. Bar represents $50 \mu \mathrm{m}$.

tural quality by dripping after thawing. The size of the ice crystals is related to the freezing conditions and time (Ballin and Lametsch, 2008).

\section{Drip loss}

Hansen et al. (2003) reported that increased drip loss caused by the freeze-thaw process is a necessary result, although it can be reduced through modification of the freezing rate and conditions. In the present study, the drip loss of frozen-thawed breast fillets after storage for $24 \mathrm{~h}$ at $4^{\circ} \mathrm{C}$ was $3.36 \%$, which was significantly higher than that of fresh ones $(0.99 \%)$ (Data not shown). However, the difference in drip loss between fresh and frozen-thawed breast fillets was not consistently significant thereafter. Increased drip loss is observed not only for chicken breast but also for beef and pork (Amvrosiadis et al., 1994; Hansen et al., 2003). These authors demonstrated that frozen-thawed beef and pork demonstrate structural changes in muscle structure due to ice crystals formed by the freezing process, resulting in increased drip loss. Increased drip loss of meat may depreciate the nutritional

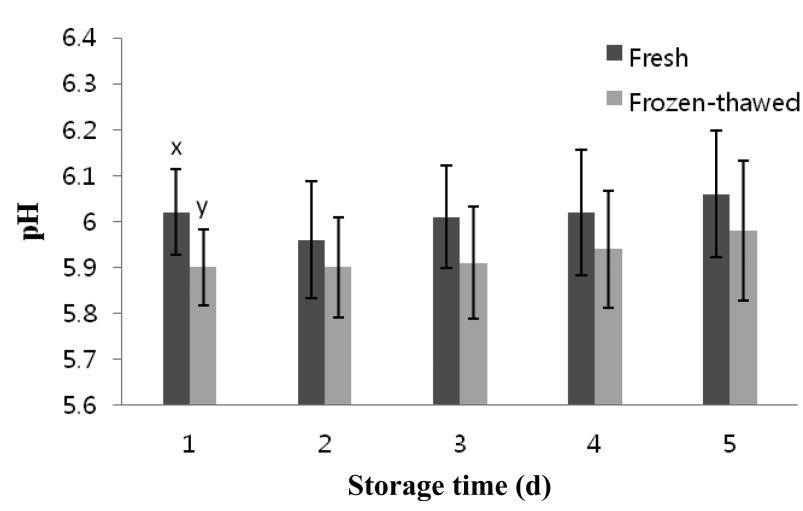

Fig. 2. pH of fresh and frozen-thawed breast fillets during storage at $4^{\circ} \mathrm{C} .{ }^{\mathrm{x}, y}$ Different letters between treatments on the same storage day differ significantly $(p<0.05)$.

quality because drip contains much of the proteins (Fischer, 2007).

\section{pH value}

The $\mathrm{pH}$ values of fresh and frozen-thawed breast fillets were not significantly different during storage, except for 1 day (Fig. 2). This result may be due to the short freezing and storage time. Previous studies have reported that the $\mathrm{pH}$ values of broiler breast meat of turkey increased up to 6.30 in proportion to storage time at $-18^{\circ} \mathrm{C}$, whereas the $\mathrm{pH}$ values of fresh chicken were in the range of 5.69 -6.13 (Sen et al., 2004; Ergonul and Kundakci, 2007).

\section{Torrymeter}

A torrymeter is generally used to evaluate the freshness of fish by measuring the modified electrical properties of the tissue (Duflos et al., 2002; Lougovois et al., 2004). The torrymeter values of fresh and frozen-thawed breast fillets were significantly different throughout the entire storage period (Fig. 3). The average torrymeter value of fresh breast fillets over five days was 11.2, whereas that of frozen-thawed ones was 2.2. The torrymeter value of fresh breast fillets was significantly decreased with increasing storage time, whereas that of frozen-thawed breast fillets remained steady. Nishimura and Lee (2004) reported that the torrymeter value of chicken breast meat gradually decreased postmortem. Additionally, the conductivity and permittivity of meat decreased with increasing storage time, resulting in modification of the electrical properties of the meat tissue (Ghatass et al., 2008). During frozen storage, meat tissue is destroyed due to increasing permeability of the cell membranes resulting from the decomposition of proteins caused by autolytic and bacterial activity. In addition, cell death generates mixed extracellular and intracellular fluids containing ions (Ghatass et al., 


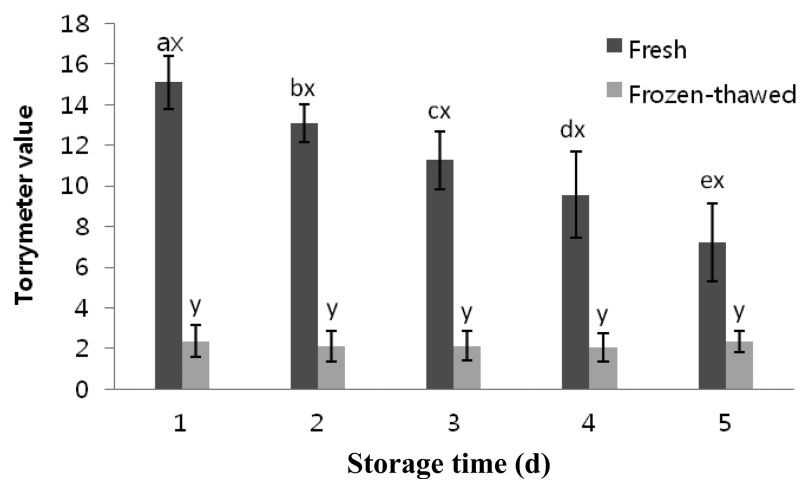

Fig. 3. Torrymeter measurements of fresh and frozen-thawed breast fillets during storage at $4^{\circ} \mathrm{C} .{ }^{\mathrm{x}, y}$ Different letters between treatments on the same storage day differ significantly $(p<0.05)$. ${ }^{\mathrm{a} e} \mathrm{e}$ Different letters among storage days with the same treatment differ significantly $(p<0.05)$.

2008). Due to the above reasons, the torrymeter value can be used to assess meat freshness related to spoilage. Further, the difference in torrymeter values between fresh and frozen breast fillets may be due to the destruction of the tissue resulting from ice crystals formed during freezing, which decrease the conductivity and permittivity of the sample.

\section{K-value}

The $K$-values of both the fresh and frozen-thawed breast fillets were significantly increased with increased storage time (Fig. 4). The fresh and frozen-thawed samples were significantly different in $K$-value at days one and three only. Postmortem, nucleotides in the meat are degraded. $K$-value is expressed as the proportion of inosine and hypoxanthine to the total amount of ATP and its degradation products. Saito et al. (1959) suggested using the $K$ -

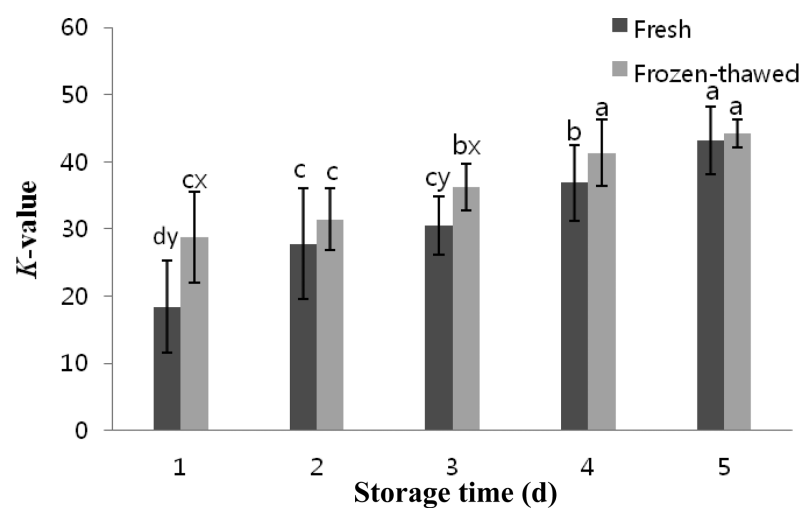

Fig. 4. $K$-value of fresh and frozen-thawed breast fillets during storage at $4^{\circ} \mathrm{C} .{ }^{\mathrm{x}, \mathrm{y}}$ Different letters between treatments on the same storage day differ significantly $(p<0.05)$. ${ }^{\mathrm{a}-\mathrm{d}}$ Different letters among storage days with the same treatment differ significantly $(p<0.05)$. value to evaluate the freshness of beef and fish (OcanoHiguera et al., 2009; Saito et al., 2009). However, Lougovois et al. (2003) reported that IMP degradation in frozen meat was slower compared to fresh one. Therefore, the results indicate that the $K$-value could not be a reliable method for identifying frozen-thawed and fresh meat, since it changes depending on the storage time and conditions.

In this study, we evaluated several current methods for the differentiation between fresh and frozen-thawed breast fillets with the goal of protecting the domestic industry and consumers. Optical microscopy was able to differentiate between fresh and frozen-thawed breast fillets; however, it may be difficult to apply in a market setting due to time and personnel constraints. The $\mathrm{pH}$ and $K$-value did not provide satisfactory results for the differentiation of frozen-thawed breast fillets from fresh ones during storage. However, torrymeter value was found to be one of the most effective and reliable screening methods for differentiation between fresh and frozen-thawed chicken breast fillets.

\section{Acknowledgement}

This study was supported from Korea Rural Development Administration Fund.

\section{References}

1. Addis, P. B. (1986) Poultry muscle as feed. In: Muscle as food. Bechtel, J. P. (ed) Academic Press, NY, pp. 370-401.

2. Al Jowder, O., Kemsley, E. K., and Wilson, R. H. (1997) Mid-infrared spectroscopy and authenticity problems in selected meats: A feasibility study. Food Chem. 59, 195-201.

3. Ambrosiadis, I., Theodorakakos, N., Georgakis, S., and Lekkas, S. (1994) Influence of thawing methods on the quality of frozen meat and the drip loss. Fleischwirtschaft $\mathbf{7 4}$, 284-287.

4. Ballin, N. Z. and Lametsch, R. (2008) Analytical methods for authenticaion of fresh vs. thaqed meat-A review. Meat Sci. 80, 151-158.

5. Carroll, R. J., Cavanaugh, J. R., and Rorer, F. P. (1981) Effects of frozen storage on the ultrastructure of bovine muscle. J. Food Sci. 46, 1091-1094.

6. Choe, J. H., Lee, J. C., and Jo, C. (2009) Relationship between the economical defects of broiler meat carcass and quality grade a with a meat grader. Korean J. Food Sci. Ani. Resour. 29, 494-499.

7. Do, G. S., Sagara, Y., Tabata, M., Kudoh, K., and Higuchi, T. (2004) Three-dimensional measurement of ice crystals in frozen beef with a micro-slicer image processing system. Int. J. Refrig. 27, 184-190. 
8. Duflos, G., Le Fur, B., Mulak, V., Becel, P., and Malle, P. (2002) Comparison of methods of differentiating between fresh and frozen-thawed fish or fillets. J. Sci Food Agric. 82, 1341-1345.

9. Ergonul, B. and Kundakci, A. (2007) Changes in quality attributes of turkey doner during frozen storage. J. Muscle Foods 18, 285-293.

10. Fischer, K. (2007) Drip loss in pork: influencing factors and relation to further meat quality traits. J. Anim. Breed Genet. 124, $12-18$

11. Ghatass, Z. F., Soliman, M. M., and Mohamed, M. M. (2008) Dielectric technique for quality control of beef meat in the range 10 kHz-1kHz. Am. Eur. J. Sci. Res. 3, 62-69.

12. Gottesmann, P. and Hamm, R. (1983) New biochemical methods of differentiation between fresh meat and thawed, frozen meat. Fleischwirtschaft 63, 219-221.

13. Grayling, R. A., Sandman, K., and Reeve, J. N. (1996) DNA stability and DNA binding proteins. Adv. Protein Chem. 48, 437-467.

14. Hansen, E., Trinderup, R. A., Hviid, M., Darre, M., and Skibsted, L. H. (2003) Thaw drip loss and protein characterization of drip from air-frozen, cryogen-frozen, and pressureshift-frozen pork longissimus dorsi in relation to ice crystal size. Eur. Food Res. Technol. 218, 2-6.

15. Lougovois, V. P., Kyranas, E. R., and Kyrana, V. R. (2003) Comparison of selected methods of assessing freshness quality and remaining storage life of iced gilthead sea bream (Sparus aurata). Food Res. Int. 36, 551-560.

16. Ngapo, T. M., Babare, I. H., Reynolds, J., and Mawson, R. F. (1999) A preliminary investigation of the effects of frozen storage on samples of pork. Meat Sci. 53, 169-177.

17. Nishimura, H. and Lee, C. (2004) Evaluation of freshness, conditioning and frozen-thawedtreatment of chicken by the torrymeter. Shokuniku ni kansuru Josei Kenkyu Chosa Seika Hokokusho 22, 191-196.

18. Ocano-Higuera, V. M., Marquez-Rios, E., Canizales-Davila, M., Castillo-Yanez, F. J., Pacheco-Aguilar, R., Lugo-Sanchez, M. E., Garcia-Orozco, K. D., and Graciano-Verdugo, A. Z. (2009) Postmortem changes in cazon fish muscle stored on ice. Food Chem. 116, 933-938.

19. Saito, K., Ahhmed, A. M., Kawahara, S., Sugimoto, Y., Aoki, T., and Muguruma, M. (2009) Evaluation of the performance of osmotic dehydration sheets on freshness parameters in cold-stored beef biceps femoris muscle. Meat Sci. 82, 260-265.

20. Saito, T., Arai, T., and Mutsuyoshi, M, (1959) A new method for estimating the freshness of fish. Bull. Jpn. Soc. Sci. Fish. 24, 749-750.

21. SAS (2002) SAS software for pc. Release 9.1 SAS institute Inc., Cary, NC, USA

22. Sen, A. R., Muthukumar, M., Naveena, B. M., and Babji, Y. (2004) Colour changes in broiler and sheep muscles during frozen storage. J. Food Sci. Tech. Mys. 41, 678-680.

23. Zhu, S., Le Bail, A., Ramaswamy, H. S., and Chapleau, N. (2004) Characterization of ice crystals in pork muscle formed by pressure-shift freezing as compared with classical freezing methods. J. Food. Sci. 69, E190-E197.

(Received 2010.8.2/Revised 2010.12.15/Accepted 2010.12.16) 